\title{
EDUCAÇÃO PROFISSIONAL E INTERAÇÃO VERBAL: DISCUSSÃ O, ARGUMENTAÇÃO E DISCURSO NO DIÁLOGO PROFESSOR-ALUNO
}

\author{
Anselmo Pereira de Lima*
}

\begin{abstract}
Resumo: Este trabalho apresenta uma análise da interação verbal ocorrida em um centro de formação profissional entre um jovem professor e um grupo de quatro alunos adultos detentores de experiência profissional na área em que estão se especializando. O texto apresenta e busca responder aos seguintes questionamentos: 1) Como se dá esse tipo de interação professor-aluno? 2) De que modo o conhecimento teórico do professor e o conhecimento prático dos alunos são postos para dialogar? 3) Como procede o professor diante dos questionamentos dos alunos? 4) Como os alunos reagem às posições teóricas assumidas pelo professor? A situação de interação aqui analisada foi gravada em áudio e vídeo e transcrita de acordo com as normas do Projeto NURC-SP. Para sua análise, foi empregada a noção de "dualismo funcional" de Lotman (1988), tal como apresentada por Wertsch e Smolka (1993). O estudo revela um processo de discussão e argumentação travado entre o professor e seus alunos em torno de aspectos teóricos e práticos da execução de um dado trabalho, o que faz circular no diálogo discursos relativos ao atrasolavanço tecnológico do Brasil. É notável a transformação dos alunos e do professor ao término do diálogo: aqueles adquirem um olhar teórico sobre sua prática e este, por sua vez, parece adquirir um olhar prático sobre sua teoria, sem - entretanto - dela abrir mão.
\end{abstract}

Palavras-chave: educação profissional, interação verbal, diálogo professoraluno

\section{Introdução}

Não é difícil encontrar trabalhos de pesquisa que - de uma forma ou de outra tratem da questão da interação professor-aluno no âmbito da educação infantil, da educação básica e da educação superior (cf. por exemplo Cazden, 2001; Furlani, 1987 e 2004; Morales, 1998/1999; Silva, 2002). Essa relativa facilidade, entretanto, muda consideravelmente quando o assunto é encontrar trabalhos que tenham - de alguma

\footnotetext{
* Doutor em Linguística Aplicada e Estudos da Linguagem pela PUC-SP e Professor da Universidade Tecnológica Federal do Paraná - UTFPR. Agradecimentos à CAPES pela bolsa de mestrado que permitiu o desenvolvimento deste trabalho.
} 
maneira - abordado o problema da interação professor-aluno no contexto da educação profissional. Não é sem razão, portanto, que Cunha (2000, p. 01-02), em tom de protesto, ressalta o fato de essa modalidade de ensino ser, dentre todas as outras, a que mais tem sido negligenciada pelos pesquisadores.

Tendo isso em vista, um dos objetivos deste texto é contribuir para que comece a haver uma mudança desse quadro e para que essa lacuna comece a se preencher. Para elaborá-lo, empreguei e baseei-me em alguns dados e análises provenientes de minha dissertação de mestrado (cf. Lima, 2005). Dessa pesquisa, com os mesmos objetivos que tenho aqui, derivam-se outros quatro textos (cf. Lima, 2009a; Lima, 2009b; Lima, no prelo a; Lima, no prelo b). Para que o contexto desses trabalhos seja compreendido, faz-se necessária a apresentação do problema que me levou a realizar a pesquisa. Faz-se necessário, além disso, que a metodologia de coleta e tratamento de dados seja detalhada. O leitor encontrará essas informações a seguir, após as quais vêm a fundamentação teórica e as análises.

\section{O problema de pesquisa}

Até o ano de 2008, fui professor de um Centro de Formação Profissional Ferroviário que oferece cursos técnicos em sistemas de transporte sobre trilhos. Essa instituição pertence a [e está inserida em] uma empresa ferroviária do estado de São Paulo, fazendo uso de um contexto autêntico de trabalho e operação ferroviária ao longo do processo de formação profissional de seus alunos. Tendo como objetivo disponibilizar para a empresa mão-de-obra qualificada na área de transporte sobre trilhos, essa escola forma técnicos ferroviários em três áreas distintas, porém relacionadas: mecânica, eletroeletrônica e transporte, especialmente de passageiros.

A instituição foi fundada em 1951. Após ter atuado por algumas décadas somente na formação profissional de jovens com até 20 anos de idade, a escola decidiu oferecer seus cursos técnicos aos empregados da empresa a partir do segundo semestre de 2002. O objetivo dessa iniciativa foi aumentar o nível de qualificação da mão-deobra já existente e, com isso, gerar para os empregados da empresa oportunidades de ascensão em suas carreiras profissionais. Atualmente, a escola funciona em período integral para os jovens - que, neste estudo, se denominam alunos estudantes (AE's) - e em período noturno para os empregados da empresa. Estes últimos são adultos e, neste estudo, são chamados alunos trabalhadores (AT's).

No primeiro semestre de 2002, quando a escola se encontrava em processo de preparação e adaptação para receber em suas salas de aula esse novo tipo de aluno, os professores da instituição começaram a discutir e a refletir sobre possíveis diferenças que encontrariam entre o trabalho de formação profissional, em sala de aula, com AE's, de um lado, e com AT's, de outro. Havia entre eles um certo consenso: o de que seria "mais trabalhoso, difícil e complexo" interagir com os alunos do noturno do que com os do diurno, visto que os primeiros "já têm experiência em trabalhos e operações ferroviárias" e, dessa forma, "exigirão mais da escola, do curso e dos professores". 
Ciente de que "a escola é, em sua tradição ocidental, muito mais disponibilizadora de saberes teóricos do que práticos" e de que "sua vocação está mais voltada para a reprodução de um saber-pensar o mundo do que para um sabertransformar o mundo" (Delamotte-Legrand, 2002, p. 130), pareceu-me - ao acompanhar e participar das discussões e reflexões de meus colegas - que eu estava diante de professores teóricos receosos de certos inconvenientes que os AT's poderiam lhes causar em função de seu conhecimento prático.

Neste estudo apresento e analiso um momento de interação de um professor $(\mathrm{P})$ com alguns alunos trabalhadores (AT's) durante a realização de uma tarefa em sala de aula. Como se dá essa interação? De que modo o conhecimento teórico do professor e o conhecimento prático dos alunos são postos para dialogar? Como procede o professor diante dos questionamentos dos alunos? Como os alunos reagem às posições teóricas assumidas pelo professor? É a essas questões que busco responder por meio das análises, antes das quais apresento a metodologia de coleta, tratamento e análise de dados e a fundamentação teórica empregada.

\section{Metodologia de coleta, tratamento e análise de dados}

Um professor e duas turmas de alunos da instituição participaram da pesquisa. Uma turma era formada por alunos jovens, os AE's, e a outra era formada por alunos adultos, os AT's. Os primeiros tinham entre 16 e 18 anos de idade e não tinham experiência profissional. $\mathrm{Na}$ época da pesquisa, estudavam em período integral no centro de formação e cursavam o ensino médio paralelamente, em outras instituições de ensino, em período noturno. Neste estudo, sua interação com o professor não é enfocada ${ }^{1}$. Os últimos tinham entre 25 e 41 anos de idade. Dentre eles, alguns já haviam feito cursos técnicos como eletrônica, eletrotécnica e mecânica. Além disso, atuavam na empresa ferroviária como mecânicos, eletricistas e encarregados de manutenção. Quando a pesquisa foi realizada, trabalhavam em período integral, já haviam concluído o ensino médio e faziam o curso técnico ferroviário em período noturno. Neste estudo, sua interação com o professor é enfocada.

O professor, responsável pela disciplina de "Desenho Técnico Eletroeletrônico" do curso técnico em "Sistemas Eletroeletrônicos de Transporte Sobre Trilhos", tinha 20 anos de idade, era Tecnólogo em Eletroeletrônica formado pela Universidade Mackenzie e trabalhava com AE's e AT's. Suas aulas não ocorriam de acordo com o modelo tradicional, isto é, com os alunos sentados ouvindo sua exposição. Eram aulas que priorizavam a execução prática de tarefas de desenho técnico: os alunos iam realizando seus trabalhos em grupos e o professor ia dando orientações a cada um, de modo individual. Chamo esse procedimento de "aula com atendimento individual". Nesse tipo de aula, o diálogo entre professor e aluno é regra, e não exceção.

1 Para um enfoque da interação do professor com os AE's, ver Lima, 2009. 
Um total de quatro aulas desse professor, duas com AE's e duas com AT's, foi gravado audiovisualmente. Cada uma dessas aulas dura, em média, cinquenta minutos. Têm-se, portanto, três horas e vinte minutos de gravação. Ao realizar as gravações, tomei o cuidado de ter o mesmo professor, o mesmo curso, a mesma disciplina e a mesma aula. Isso me ofereceu um excelente parâmetro de comparação entre o trabalho do professor com AE's, de um lado, e com AT's, de outro. Apesar de eu não enfocar neste trabalho a interação do professor com AE's, é importante ressaltar esse ponto porque foi o conhecimento da interação do professor com AE's que me levou a identificar a necessidade de desenvolver este estudo do modo como o desenvolvi.

Nas aulas, os alunos projetaram circuitos de instalações elétricas no desenho (planta) de uma residência. Isso foi feito com o emprego de recursos gráficos que representavam elementos como fios, lâmpadas, tomadas, etc. As orientações que os alunos recebiam eram dadas pelo professor sempre com base nos desenhos por eles realizados.

A transcrição das aulas foi feita de acordo com as normas do projeto de estudo da norma linguística urbana culta, conhecido como Projeto NURC (cf. Marcuschi, 2003: 09-13; Dino Preti, 2001: 11-12; Dionísio, 2000/2006: 76). Ao transcrever os dados, fiz uso das imagens gravadas para registrar na transcrição a ocorrência de certos marcadores conversacionais não linguísticos, tais como o olhar, o riso, os gestos, etc. (cf. Urbano, 2001, p. 87). São os seguintes os símbolos de transcrição adotados: ... = qualquer pausa; ((bateu firme) $)=$ comentários do transcritor; / = truncamento; aí:: = prolongamento de vogal ou consoante; [ = simultaneidade de vozes; MAIÚSCULAS = entonação enfática; ( ) = incompreensão de palavras ou segmentos; (puxa daqui ali) = suposição do que se ouviu; i-sso = silabação.

\section{Fundamentação teórica}

Para a análise dos dados, lanço mão da noção de "dualismo funcional" de Lotman (1988), tal como apresentada por Wertsch e Smolka (1993). Dizem os autores que Lotman vê quase todos os textos como instrumentos de realização de duas funções básicas: 1) comunicar significados (função unívoca); e 2) criar novos significados (função dialógica). Dizem, ainda, que Lotman, em seus estudos, apresenta essas duas funções como presentes em quase todos os textos, mas com a predominância de uma sobre a outra.

A função unívoca predomina em textos em que o objetivo principal é a transmissão de informações que não podem ser questionadas, enquanto a função dialógica, baseada no tipo de dialogia que está no centro das análises bakhtinianas, predomina em textos em que há transmissão de informações que propiciam um movimento no sentido de se negociar e criar novos significados. Em outras palavras, na função dialógica há o envolvimento de múltiplas vozes (discursos), que se interanimam dialogicamente desde o início da interação. É importante ressaltar que a função unívoca e a função dialógica correspondem, respectivamente, às chamadas força centrípeta e 
força centrífuga, que podem estar presentes em qualquer texto (cf. Clark; Holquist, 1984/2004, p. 35; Faraco, 2003, p.67; di Fanti., 2009a; 2009b, p. 121-123).

Com efeito, a propósito da interação, como diz Allwright (1984, p. 159), "nada pode mudar o fato de que a interação é, por definição e na prática, uma forma de coprodução" de significados. A meu ver, co-produzir significados diz respeito a ter a oportunidade de se discutir quaisquer assuntos que estejam em questão. Segundo Brookfield e Preskill (1999, p. 03), a "discussão é um valioso e inspirador meio para se revelar a diversidade de opinião que jaz logo abaixo da superfície de quase toda e qualquer questão complexa". A meu ver, não pode haver discussão sem que se lance mão também de mecanismos de argumentação, pois acredito que, por mais dispostas a negociar que estejam as partes envolvidas na discussão, um participante sempre tentará convencer o outro de seu ponto de vista.

Para Carraher (1983, p. 04-05), "quando uma pessoa apresenta e defende idéias diante de outros, ela está fazendo argumentação", ou seja, está apresentando argumentos, os quais correspondem a "qualquer conjunto de afirmações que inclua, pelo menos, uma conclusão". Carraher (idem) diz ainda que "quem apresenta um argumento, seja uma criança, um professor universitário, pedreiro ou filósofo, usa premissas, às vezes chamadas evidências, para defender ou fundamentar sua conclusão", pressupondo que "o ouvinte deve também aceitar a conclusão se levar as evidências em consideração".

Considerando o processo que vai da função unívoca à dialógica, da função dialógica à interação, da interação à discussão e da discussão à argumentação, meu objetivo neste trabalho será o de mostrar como esse processo se realiza em um atendimento P-AT em uma sala de aula que se configura, como diria Rajagopalan (2003, p. 105), como "um autêntico espelho das contradições e tensões que marcam a realidade que se verifica fora da escola", mas que permite sim a criação dialógica de novos significados tanto para os alunos quanto para o professor.

Nas análises apresentadas a seguir, o leitor encontrará um predomínio da descrição dos dados. No momento seguinte, o das considerações finais, o leitor encontrará um cotejamento mais sistemático (porém sintético) dessa descrição com os fundamentos teóricos que acabo de apresentar.

\section{Análise dos dados}

O conjunto dos dados de que disponho apresenta um total de 11 atendimentos do professor a alunos trabalhadores. Neste trabalho, apresentarei uma análise do atendimento de número 7, linhas de 1150 a 1695 do corpus. Ele traz uma discussão do professor com quatro alunos (AT, AT1, AT2 e AT3) a respeito do emprego (ou não) do sistema de aterramento em tomadas dos circuitos de instalações elétricas brasileiras e uma apreciação do que isso implica. Por tratar-se de um atendimento longo, cuja 
totalidade pode ser consultada em Lima (2005, p. 246-255), utilizo-me aqui de uma sequência de recortes representativos da interação do professor com os alunos. $O$ seguinte trecho do atendimento mostra o docente dando um exemplo do que se faz na prática de trabalho e apresentando argumentos teóricos para contestar isso:

\section{Atendimento 7, linhas de 1195 a 1210}

P: $\quad$ não pode a gente às vezes usa:... ah vamo(s) aterrar um negócio liga lá no no neutro do cento e dez é perigoso... perigoso porque se algum se dá um curto por exemplo entre um neutro e uma fase... o que era neutro passa a ser fase... aí (que estoura) tudo ((faz que sim $))$

AT2: é ((os alunos olham para o professor e fazem que sim))

P: por onde ia ter que fugir vai estar chegando corrente ((sorrindo $))$... aí:: arrebenta... ((faz que sim, os alunos ouvem e olham para o professor))

AT3: no caso aqui sempre na na na...

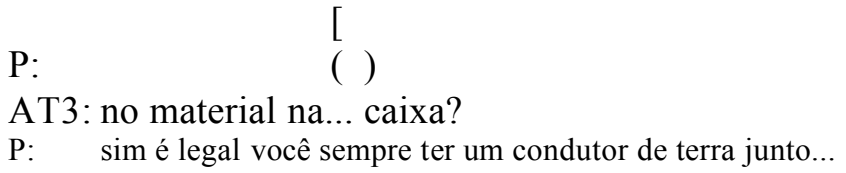

Em primeiro lugar, o professor apresenta aos alunos o que se faz na prática: "a gente às vezes usa:... ah vamo(s) aterrar um negócio liga lá no no neutro do cento e dez". Em seguida, apresenta-lhes uma avaliação disso: "é perigoso...", e prossegue justificando seu ponto de vista a partir de argumentos teóricos: "perigoso porque se algum se dá um curto por exemplo entre um neutro e uma fase... o que era neutro passa a ser fase... aí (que estoura) tudo ((faz que sim))" e "por onde ia ter que fugir vai estar chegando corrente ((sorrindo))... aí:: arrebenta... ((faz que sim, os alunos ouvem e olham para o professor))". As colocações do professor suscitam uma pergunta da parte de um dos AT's e o professor pode então concluir enfatizando a necessidade de se empregar o sistema de aterramento "correto" em circuitos cento e dez: "sim é legal você sempre ter um condutor de terra junto...".

Parece que o que o professor faz nesse trecho é "entrar" no mundo do trabalho prático com seus alunos e explicitar seus procedimentos, os quais parecem ser conhecidos dos alunos, e, em seguida, avaliar esses procedimentos como inadequados, justificando sua avaliação teoricamente, inclusive apresentando as conseqüências indesejáveis que eles podem trazer: "aí (que estoura) tudo" e "aí:: arrebenta...". O resultado é que o professor, após contestar a prática, parece conseguir convencer seus alunos e, assim, fazer prevalecer o ponto de vista teórico sobre um certo ponto de vista prático.

$\mathrm{O}$ atendimento avança e, em um dado momento, quando o professor prosseguia com algumas orientações teóricas, um dos AT's quer intervir apresentando uma forma de execução da instalação de circuitos elétricos baseada naquilo que ele conhece de sua prática, inclusive argumentando para defender seu ponto de vista. $\mathrm{O}$ trecho a seguir apresenta a discussão: 


\section{Atendimento 7, linhas de 1250 a 1285}

P: $\quad$ cento e dez também primeiro... tá? vou fazer o desenho aqui da tomada pra você entender...

AT's:fase e neutro ((fala baixa dos alunos entre si enquanto o professor desenha))

P: fa::se e neutro

AT: mas aí (nem) precisa do aterramento

P: $\quad$ preci::sa ((AT2 faz que sim enquanto observa o desenho que o

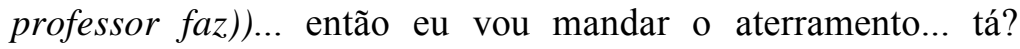
porque que eu não po::sso... confundir nem juntar neutro com proteção? ((AT2 e AT3 observam o trabalho, AT olha para o professor ))... tá? primeiro... o neutro ( ) é zero volts

AT:

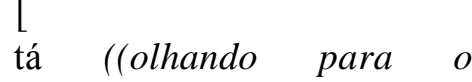

professor)) pera pera o neutro o neutro não é a mesma coisa não não é um aterramento? por exemplo você pega um quadro de força da eletropaulo aí ((testa franzida))... aquele neutro é um cabo que é enterrado

P:

lapiseira e examina o desenho)) mas é outra coisa

[

ah ((AT2 pega a

AT: não é não é o neutro?

[

P: $\quad$ não é a mesma coisa... ele tem um aterramento pra ajudar a eletropaulo só pra isso

AT2: ((dirigindo-se ao AT3 a seu lado)) é eu acho que eu já até vi aqui ((conversa paralela entre alunos))

P:

agüenta... o fio não vai suportar

porque se não não

\section{[}

AT2:

se você tem::... ((todos prestam atenção

ao AT2)) um curto aqui... você manda as fases e o neutro queima a tua lâmpada e o::

P: $\quad$ se entra em curto fase fase... justamente... queima tudo

AT2: que estiver no circuito

Nota-se que o professor vinha apresentando algumas explicações ao grupo de alunos e, para ilustrá-las melhor, recorreu ao desenho: "vou fazer o desenho aqui da tomada pra você entender...". No momento em que desenhava, seus alunos o acompanhavam. Exatamente nessa ocasião, um dos alunos (o AT) questiona: "mas aí (nem) precisa do aterramento", a que o professor responde diretamente (o alongamento do "i" indica ênfase do professor dada ao "equívoco" do aluno): "preci::sa". O professor parece não querer discutir a questão e prossegue com suas explicações. Porém, o AT não se dá por satisfeito e 1) o interrompe com um questionamento: "tá ((olhando para o 
professor)) pera pera o neutro o neutro não é a mesma coisa não não é um aterramento?"; 2) defende seu ponto de vista com um argumento na forma de um exemplo prático: "por exemplo você pega um quadro de força da eletropaulo aí ((testa franzida))... aquele neutro é um cabo que é enterrado".

O professor não concorda com o aluno e diz: "ah mas é outra coisa". Seguem explicações do professor a esse respeito, apoiadas pela concordância do AT2. O AT parece já não insistir na questão com tanta ênfase: “não é não é o neutro?", pergunta na qual já se nota a ausência de certeza com a qual fazia inicialmente suas afirmações. Nesse caso, vê-se que o AT se manifesta para questionar a teoria em função do conhecimento prático que traz consigo. Porém, o argumento teórico do professor goza de maior autoridade e parece ser mais convincente que o do aluno, prevalecendo mais uma vez, sendo inclusive apoiado por um outro AT que fazia parte do grupo em atendimento.

O diálogo avança e surgem outras questões de confronto entre a teoria que o professor apresenta e o conhecimento prático que os alunos trazem consigo. No trecho a seguir, o professor estava explicando a construção do sistema de aterramento como um todo. O AT apresenta aquilo que conhece da teoria para confrontar esse conteúdo com aquilo que o professor diz:

\section{Atendimento 7, linhas de 1415 a 1425}

P: não não elas (( três barras de aterramento $))$ são colocadas certinho

AT:

na vertical

[ na ver-ti-cal

P: $\quad$ é normalmente é por um uma própria:: condição ( )

[

AT:

(geralmente) ( )... já

vi:: com uma só ((mostra o dedo indicador para o professor fazendo o um))

P:

normalmente usa uma só... vai proteger? vai proteger melhor do que nada... só que não é tão eficiente quanto este método aqui

Observa-se que o professor falava a respeito da colocação de barras de aterramento (três ao todo) no projeto de instalações elétricas. O AT, ao que parece, já evitando um confronto direto com aquilo que diz o professor, faz a seguinte afirmação baseado em sua experiência: "(geralmente) ( )... já vi:: com uma só ((mostra o dedo indicador para o professor fazendo o um)". O professor responde com "normalmente usa uma só... vai proteger? vai proteger melhor do que nada... só que não é tão eficiente quanto este método aqui". Verifica-se que a referência à prática entra no discurso tanto do aluno como no do professor através de advérbios como "geralmente" e 
"normalmente". De fato, eles apontam para aquilo que é "geral" em oposição ao específico, para aquilo que é "normal" em oposição ao "anormal". O que seria o "geral" e o "normal"? A prática. O que seria o "específico" e o "anormal"? A teoria.

Parece que aquilo que vai aos poucos ocorrendo nesse atendimento é o convencimento dos alunos de que realmente é necessário empregar adequadamente o sistema de aterramento em instalações elétricas, prevendo-o inclusive no projeto. Parece que, aos poucos, os AT's vão deixando de lado uma certa postura "anti-teoria" e "antinorma" que possuíam inicialmente e vão adotando um olhar teórico sobre sua prática e sobre a prática que conhecem. Os AT's, como se poderá verificar mais adiante por meio dos exemplos, vão aos poucos tornando-se "cúmplices" do professor, ou seja, vão se "aliando" a ele, passando a adotar o mesmo discurso.

O seguinte trecho mostra os AT's questionando o professor quanto à exigência do aterramento pela norma técnica. Surge, com isso, um exemplo concreto da não conformidade da execução prática do trabalho com a prescrição apresentada pela norma e das conseqüências que isso traz:

\section{Atendimento 7, linhas de 1470 a 1495}

AT2: é exigido que se faça aterramento?

AT:

[

P: $\quad$ sim a norma pede... porque hoje em dia praticamente todo aparelho que você compra ele vem com aterramento... já vem já com um ponto de terra

AT: um outro dia foi um camarada lá ((expressão/entonação de reprovação))... ele pegou lá não sei se foi uma torneira que ele pegou lá ((sobreposição de vozes incompreensíveis)) ( ) acho que foi um chuveiro e veio quatro fio verde [

P: $\quad$ veio quatro fio verde

AT: o que o cara fez? pegou um prego ((segura a lapiseira no ar como se fosse um prego, bate com o dedo como se fosse um martelo)) tum tum tum na parede e enrolou ((enrola um fio imaginário na lapiseira))

[

P: $\quad$ e:: e e enrolou não pode i:sso: detona tudo... não aterra NAda... ((os alunos pensativos observam e ouvem o professor $)$ )

AT: o cara meteu um prego lá na parede lá bicho

P: $\quad$ é::

AT: enrolou lá pra não dar choque ((tom de riso, os colegas riem))

P: tem gente que: enrola na torne::ira: ahn enrola no:: ( )

Inicialmente, após todas as explicações do professor sobre a importância do sistema de aterramento, o AT2 o questiona com "é exigido que se faça aterramento?". O $\mathrm{AT}$, percebendo onde seu colega queria chegar, parafraseia a pergunta com "a norma 
pede isso?". O professor responde imediatamente: "sim a norma pede..." e prossegue com uma justificativa para sua afirmação e para o fato de a norma "exigir/pedir" isso: "porque hoje em dia praticamente todo aparelho que você compra ele vem com aterramento... já vem já com um ponto de terra". O que diz o professor deixa claro para os alunos que se os aparelhos eletroeletrônicos vêm com um tipo de tecnologia contendo o aterramento, as tomadas onde eles serão ligados devem também, pela norma, conter esse sistema.

As afirmações do professor suscitam no AT uma atitude responsiva ativa e este vai agora, como de costume nesse atendimento, apresentar um exemplo vivenciado em sua prática. Dessa vez corroborando o que muitas vezes diz o professor sobre a inadequação de certos procedimentos práticos. Ele fala de um certo "camarada" que veio instalar certo aparelho elétrico, uma "torneira" elétrica talvez, a qual veio com fiação adequada ("quatro fio verde") para que se fizesse seu aterramento. Porém, o "cara" tomou um "prego" e o colocou na parede com um "martelo" e nele enrolou a fiação do aterramento. O aluno, como se vê no trecho, simula a execução prática desse trabalho para dar ênfase a seu relato.

O professor não demora em avaliar esses procedimentos: "não pode i:sso: detona tudo... não aterra NAda...”. É a teoria contestando certa execução prática de um trabalho por meio do discurso do professor e, agora, também do discurso do aluno. O que segue após isso é uma espécie de ridicularização do "cara" no discurso dos AT's: "o cara meteu um prego lá na parede lá bicho" e "enrolou lá pra não dar choque ((tom de riso, os colegas riem)".

No trecho a seguir, vê-se que o professor prossegue em suas discussões com os AT's, agora fazendo uma apreciação das condições de execução prática dos serviços de instalações elétricas no Brasil como um todo, especialmente no que se refere ao emprego adequado ou não do sistema de aterramento:

\section{Atendimento 7, linhas de 1510 a 1525}

P: não é que é cento e dez você pode ter equipamento de duzentos e vinte sem aterramento uma lâmpada duzentos e vinte não precisa de aterramento... na verdade até o cento e dez precisava ter aterramento... (é que não é costumeiro) aqui no Brasil não teve essa cultura... você ir pegar e ter uma um terra na sua tomada

AT1:

[

P: $\quad$ você liga lá a tomada de qualquer jeito... já comprou aparelho importado?

AT1: já

P: que vem com pino um maior que o outro?

AT2: já... eu achei que estava com defeito 
Ao discorrer sobre as características técnicas das instalações elétricas (a necessidade de se ter ou não o sistema de aterramento em circuitos elétricos de 110 ou 220 volts), o professor faz uma crítica aberta ao Brasil quanto à sua negligência em não adotar e seguir certas especificações técnicas. Ele revela que, apesar de ser necessário, o sistema de aterramento não é empregado nesses tipos de circuito no país. Diz o professor: "aqui no Brasil não teve essa cultura... você ir pegar e ter uma um terra na sua tomada". O professor diz ainda que as tomadas são ligadas sem critérios, ou seja, sem norma: "você liga lá a tomada de qualquer jeito".

Para ilustrar e confirmar a veracidade de suas afirmações, o professor questiona seus próprios alunos, fazendo as seguintes perguntas: "já comprou aparelho importado que vem com pino um maior que o outro?". Os alunos respondem que sim e um deles revela ter achado que o aparelho estava com defeito: "eu achei que estava com defeito".

A exposição anterior permite tirar algumas conclusões fundamentais. Se os circuitos elétricos de 110 e 220 volts precisam de receber um sistema de aterramento adequado e, no entanto, no Brasil, isso não acontece, segue-se que tanto os profissionais que executam as instalações elétricas (os "camaradas" e os "caras") quanto aqueles que contratam seus serviços ou trabalham de maneira incorreta ou não possuem o conhecimento da maneira adequada de se executar o trabalho. O último caso, o do desconhecimento, parece ser o mais provável, como aponta a resposta do aluno, o qual também é profissional no mercado: "eu achei que estava com defeito".

O fato de o professor ter usado o exemplo de um aparelho importado para ilustrar e confirmar suas afirmações, aliado ao fato de ele ter criticado o Brasil como um país que não teve a cultura de seguir certa especificação técnica, aponta para o atravessamento de seu discurso pelo discurso do que vou chamar "atraso tecnológico". Em outras palavras, enquanto outros países fazem aquilo que é certo, seguindo as especificações técnicas e produzindo aparelhos eletroeletrônicos que dão evidências disso (os importados), o Brasil, por uma questão cultural, faz aquilo que é errado ao não seguir as especificações técnicas, chegando sua população a nem mesmo saber como lidar com aparelhos importados, os quais são fabricados para circuitos elétricos projetados segundo as normas. Sobre essa mesma questão, apresento ainda o seguinte exemplo:

\section{Atendimento 7, linhas de 1550 a $1560, \mathrm{AT}$}

AT2: eu vou ligar aquilo aonde? minha casa não tem

P: $\quad$ então... por isso que:... faz falta... é que... por exemplo aqui no Brasi::1 hahn ((interjeição que expressa descrença)) aqui no Brasil a gente não tem essa cultura de fazer o aterramento na tomada

Percebe-se que o professor, ao falar do país, emprega a interjeição de descrença "hahn": a imagem que ele tem do Brasil no que se refere ao cumprimento das normas técnicas é negativa, e ele acaba também transmitindo esses valores a seus alunos. Um detalhe de fundamental importância nesse momento é que, conforme foi apresentado anteriormente, o professor fala de aparelhos importados. $\mathrm{O}$ importado aponta para $\mathrm{o}$ 
estrangeiro, outros países. Que países serão esses? Também ao dizer "aqui no Brasil a gente não tem essa cultura de fazer o aterramento na tomada", o professor também quer dizer que em outros países isso realmente acontece, há essa "cultura" de que ele fala. Mais uma vez pergunto: que países serão esses? Creio que o seguinte exemplo possa responder a essa questão na totalidade:

\section{Atendimento 7, linhas de 1565 a 1575, AT}

P: $\quad$ realmente é uma estrutura que a gente não teve esse costume agora você vai numa casa ameriCA:na uma casa... européia lá na na França Inglaterra todo mundo tem aterramento tem ( )

AT2: $\quad$ toda tomada tem três?

P: NÃo... eu já vi tomada de aterramento diferente ((várias vozes sobrepostas seguem))

Os países de que o professor fala são os Estados Unidos e alguns países europeus como França e Inglaterra. Percebe-se que o discurso do professor não é apenas atravessado pelo discurso do "atraso tecnológico" de seu país, mas também pelo seu oposto, o do "avanço tecnológico" de outros países. Com efeito, mesmo que implicitamente, ao se falar em atraso, inevitavelmente fala-se também em avanço, pois seria impossível falar de algo ou alguém que está "atrás" sem pelo menos pensar, ter em mente, fazer referência a algo ou alguém que está na "frente".

Voltando ao contexto do Brasil, o professor esclarece aos alunos que nos aparelhos eletroeletrônicos em geral é "padrão" existir não só a previsão de que haverá sistema de aterramento nas tomadas ou circuitos em que serão ligados, mas também a previsão do posicionamento correto dos terminais de captação de energia (fase e neutro) no momento da instalação dos aparelhos. Porém, diz o professor, o mesmo não acontece com as tomadas e circuitos: estes não preveem que neles serão ligados aparelhos que necessitam de um sistema de aterramento e de posicionamento adequado desses terminais. O seguinte trecho ilustra bem essa discussão:

\section{Atendimento 7, linhas de 1625 a 1650 , AT}

P: no aparelho é padrão... então padrão (porque já veio de fábrica)

AT2:

$$
\text { [ }
$$

invertida

ah é a tomada que vai estar

P: a tomada que pode estar invertida então

AT: o que pode ocorrer ne ne ne ne numa inversão?

$\mathrm{P}$ : várias coisas... ((o professor fala, os alunos o ouvem $e$ observam atentamente)) pode queimar o apare::lho se o 
aparelho for muito sensível pode ter esse problema de... traze::r a fase ( )

AT2:

[ de aparelho?

mas a tomada não é feita para Esse tipo

AT: a tomada não o plugue o plugue

P: $\quad$ porque a tomada o plugue ela é feita só que... é

erro no::Sso

AT2:

P: $\quad$ é erro nosso montagem uma falta de conhecimento... ((o AT3

faz que sim))

AT2: é erro nosso então?

P: $\quad$ é... é... falta de conhecimento... se você for lá e perguntar pra ele ( ) como está a tomada o cara não vai querer saber se é fase se é neutro ((bate uma mão na outra em gesto de "pouco importa"))

O professor inicia dizendo a seus alunos que é "padrão" nos plugues dos aparelhos eletroeletrônicos o posicionamento dos terminais de captação de energia "fase" e "neutro", um "padrão" que já vem de fábrica: "no aparelho é padrão... então padrão (porque já veio de fábrica)"; o AT2 conclui: "ah é a tomada que vai estar invertida", e o professor confirma: "a tomada que pode estar invertida então". Segue-se uma pergunta do AT quanto às consequências dessa inversão e a resposta do professor.

Tendo em vista que os plugues dos aparelhos vêm de fábrica obedecendo aos padrões técnicos, ou seja, às normas técnicas, ao passo que o mesmo não se dá com as tomadas das instalações elétricas nas quais serão instalados, o professor conclui: "é erro nosso montagem uma falta de conhecimento...". O professor, portanto, classifica essa inadequação como "erro de montagem" que pode ser atribuído a "falta de conhecimento" do montador, ou seja, do eletricista ou daquele que executa o trabalho prático, "ele", o "cara": "se você for lá e perguntar pra ele ( ) como está a tomada o cara não vai querer saber se é fase se é neutro ((bate uma mão na outra em gesto de "pouco importa"))". Mais uma vez, vê-se que o profissional que executa esse trabalho prático é mencionado como "o cara", o qual, como se pode concluir pela fala do professor, é indiferente àquilo que faz, "não quer saber". Assim, parece haver a desqualificação da execução prática do trabalho e de seu executor em função do desconhecimento teórico aí envolvido, bem como de seu descaso: "não quer saber".

O atendimento tem sua conclusão com essa questão e com a verificação daquilo que diz o professor feita na própria sala de aula pelos alunos, como mostra o trecho:

\section{Atendimento 7, linhas de 1680 a 1655, AT}

AT2: não deve se::r norma né? ((olha para o professor e faz que sim pedindo confirmação))... no lado tal 
P: $\quad$ inclusive na tomada é que aqui não dá pra gente ver aí não mostra... viu I.?

AT2: viu I.? então deve ter norma

[

P: aí não mostra mas lá tem... pode reparar naquela toma::da... que um dos lados tem um "W"... é ali ali é o neutro...

AT2: é ali está vendo? de um lado ou no meio?...

P: $\quad$ ali tem tem uma identificação ((pega na tomada junto com o AT e a examina)) em um dos pinos tem uma letrinha de um lado... é para diferenciar um pino do outro...

AT2: e daí deve ser a norma também...

AT: tem mesmo

P: tem? tem uma letrinha aí né?

AT: ( )

AT2: agora falta colocar norma na na na na na ( )

P: $\quad$ na instalação é que é uma falta de conhecimento... não só... é nossa e de quem vem instalar... não conhece...

AT2: ( ) ((arregala os olhos))

Verifica-se que o professor retoma, ao fim do atendimento aos AT's, a seguinte fala: "é uma falta de conhecimento... não só... é nossa e de quem vem instalar... não conhece....".

\section{Conclusão}

Neste texto, após apresentar o problema de pesquisa no item 1, lancei as seguintes questões e me propus a respondê-las: 1) Como se dá a interação do professor com os alunos trabalhadores, os AT's? 2) De que modo o conhecimento teórico do professor e o conhecimento prático dos alunos são postos para dialogar? 3) Como procede o professor diante dos questionamentos dos alunos? 4) Como os alunos reagem às posições teóricas assumidas pelo professor? Penso que o conjunto de tudo que acabo de apresentar responde em grande parte a esses questionamentos. Faz-se, entretanto, necessário tecer as seguintes considerações finais a título de ampliação e sistematização do modo como esse conjunto responde a essas indagações.

Tentei mostrar - por meio da análise - o dualismo e o conflito inicial existentes entre a teoria presente no discurso do professor e a prática presente no discurso dos alunos trabalhadores. Tentei mostrar também como, por meio da produção de textos orais em que predomina a função dialógica, os alunos e o professor, fazendo uso da oportunidade de interagir, discutir e argumentar, questionam-se mutuamente quanto às experiências e conhecimentos que trazem consigo, sendo o resultado disso o benefício 
dos alunos trabalhadores, que assim parecem ter adquirido um olhar teórico sobre sua prática (do qual demonstravam inicialmente estar destituídos), e do professor, que parece ter desempenhado bem seu papel, além de, por sua vez, ter adquirido um olhar prático diferenciado sobre a teoria que "professa", sem, no entanto, dela abrir mão.

No início do atendimento do professor aos alunos trabalhadores, percebe-se com clareza a existência de dois discursos: o da teoria, segundo o qual o emprego de um sistema de aterramento em circuitos elétricos é imprescindível, e o da prática, segundo o qual o emprego desse sistema é desnecessário. O primeiro é o discurso do professor, o segundo - pode-se considerar - é o discurso dos alunos. Em cada um desses discursos, independentemente um do outro, isto é, antes de seu contato dialógico, predomina uma certa função unívoca, pois as informações por eles veiculadas não podem ser questionadas no interior de cada discurso de modo individual e isolado. É apenas quando entram em contato na situação de atendimento que o discurso da prática se manifesta para questionar o discurso da teoria. O resultado, por meio do diálogo do professor com os alunos, é a produção de um texto/discurso oral em que - visivelmente - passa a predominar a função dialógica: esses dois discursos se questionam/estranham mutuamente. Com esses questionamentos e com as discussões resultantes, há a apresentação de informações que desencadeiam uma dinâmica na qual há negociação e criação de novos significados, isto é, de novos pontos de vista sobre o mesmo objeto.

Observa-se nesse processo que - por meio da interação, da discussão e da argumentação - o professor vai gradualmente convencendo os alunos de que o ponto de vista da teoria é digno de credibilidade, não podendo ser questionado. Pode-se dizer, portanto, que ocorre no atendimento analisado uma dinâmica em três fases: $1^{\text {a }}$ ) no discurso do professor, de um lado, e no discurso dos alunos, de outro, predomina uma certa função unívoca; $2^{\mathrm{a}}$ ) com o encontro e o embate entre esses dois discursos na situação de atendimento do professor aos alunos, é aberto um espaço de interação, discussão e argumentação cujo resultado é a produção de um texto/discurso em que predomina a função dialógica em grau máximo; $3^{\mathrm{a}}$ ) com o desenvolvimento do processo interacional, os alunos vão gradualmente se convencendo do ponto de vista do professor, deixando de questioná-lo e passando, junto com o professor, a defendê-lo. Passa-se, pois, no diálogo, de uma função unívoca a uma função dialógica e desta a uma nova função unívoca partilhada pelo professor e pelos alunos. Isso, ao menos, até que a prática volte a dialogizar o monólogo inerente a toda função unívoca do discurso teórico.

\section{Referências bibliográficas}

ALLWRIGHT, R. L. The importance of interaction in classroom language learning. Applied Linguistics, v.5, n.2, p. 156-171, 1984.

BROOKFIELD S. \& PRESKILL, S. Discussion as a way of teaching: tools and techniques for democratic classroom. San Francisco: Jossey-Bass Inc., 1999. 
CARRAHER, D. W. (1983). Senso Crítico: do dia-a-dia às ciências humanas. São Paulo: Livraria Pioneira, 1983.

CAZDEN, C. B. Classroom discourse: the language of teaching and learning. 2nd. ed. Portsmouth, NH: Heinemann, 2001.

CLARK, K.; HOLQUIST, M. Mikhail Bakhtin. São Paulo: Perspectiva, 1984/2004.

CUNHA, L. A. O ensino de ofícios artesanais e manufatureiros no Brasil escravocrata. São Paulo: Editora Unesp; Brasília, DF: Flacso, 2000.

DELAMOTTE-LEGRAND, R. A profissão de professor: relações com os saberes, diálogo e colocação em palavras. In: SOUZA-E-SILVA, M. C. P., FAÏTA., D. (orgs.). Linguagem e trabalho. São Paulo, Cortez, 2002.

DI FANTI, M. G. C. Força centrífuga. In: FLORES, V. N. et al. Dicionário de linguística da enunciação. São Paulo: Contexto, 2009a.

- Força centrípeta. In: FLORES, V. N. et al. Dicionário de linguística da enunciação. São Paulo: Contexto, 2009b.

DIONÍSIO, A. P. Análise da conversação. In: MUSSALIM, F.; BENTES, A. C. B. Introdução à linguística II: domínios e fronteiras. 5. ed. São Paulo: Cortez, 2000/2006.

FARACO, C. A. (2003). Linguagem e diálogo: as ideias linguísticas do Círculo de Bakhtin. Curitiba: Criar.

FURLANI, L. M. T. Autoridade do professor: Meta, mito ou nada disso? São Paulo: Cortez (Questões da nossa época, 39), 2004.

FURLANI, L. M. T. Autoridade: meta, mito ou nada disso? A resposta de professores universitários. São Paulo, PUC-SP, dissertação de mestrado, 1987.

LIMA, A. P. Educação profissional e interação verbal: a função do verbo modal "poder" no diálogo professor-aluno. Linguagem em Dis(curso), v. 09, n.1, jan./abr., 2009a. Disponível em http://www3.unisul.br/paginas/ensino/pos/linguagem/0901/090102.pdf

. Teoria versus prática: polêmica na interação professor-aluno durante a execução de uma tarefa. ReVEL, v. 07, n. 13, 2009b. Disponível em http://www.revel.inf.br/site2007/_pdf/15/artigos/revel_13 teoria_versus_pratica.pdf

. (no prelo-a). Educação profissional e interação verbal: a função dos verbos modais "ter que" e "precisar" no diálogo professor-aluno.

. (no prelo-b). Educação profissional e interação verbal: as perguntas dos alunos, as respostas do professor. 
. A interação professor-aluno em um Centro de Formação Profissional Ferroviário. 2005. Mestrado em Linguística Aplicada e Estudos da Linguagem. Pontifícia Universidade Católica: São Paulo. Disponível em http://www.pucsp.br/pos/lael/lael-inf/def teses.html.

MARCUSCHI, L. A. Análise da conversação. 5. ed. São Paulo: Ática, 2003.

MORALES, P. A relação professor-aluno: o que é, como se faz. Trad. Gilmar Saint'Clair Ribeiro. 3. ed. São Paulo: Loyola, 1998/1999.

LOTMAN, Y. M. Text within a text. Soviet Psychology, v. 26, n. 3, p. 32-51, 1988.

PRETI, D. (org.). Análise de textos orais. 5 ed. São Paulo, Humanitas (Projetos Paralelos: V.1.), 2001.

RAJAGOPALAN, K. Linguística aplicada: perspectivas para uma pedagogia crítica. In: Por uma lingüística crítica: linguagem, identidade e a questão ética. Säo Paulo: Parábola, 2003.

SILVA, L. A. Estruturas de participação e interação na sala de aula. In: PRETI, D. (org.) Interação na fala e na escrita. São Paulo: Humanitas (Projetos Paralelos: V. 5.), 2002.

URBANO, H. Marcadores conversacionais. In: PRETI, D. Análise de textos orais. 5. ed. São Paulo: Humanitas. (Projetos Paralelos - NURC/SP - 01), 2001.

WERTSCH, J.; SMOLKA, A. L. B. Continuando o diálogo: Vygotsky, Bakhtin e Lotman. In: H. Daniels (org.) Vygotsky em Foco: Pressupostos e desdobramentos. Campinas: Papirus, 1993.

\begin{abstract}
This article presents an analysis of the verbal interaction that took place in a vocational school between a young teacher and a group of four adult students who have professional experience in the area they are specializing in. The text presents and aims to answer the following questions: 1) How does this kind of teacher-student interaction take place? 2) In what way do the teacher's theoretical knowledge and the students' practical knowledge dialog? 4) How do the students react to the teacher's theoretical positions? The interaction situation analysed in this article was recorded on film and transcribed in accord with the standards of the NURC-SP Project. Lotman's notion of "functional dualism" (1988), as presented by Wertsch and Smolka (1993), was employed in the analysis. The study reveals a process of discussion and argumentation that takes place between the teacher and his students around theoretical and practical aspects of the execution of a certain job. It also reveals discourses related to Brazil's technological delay/advance. At the end of the dialog, the change observed in the students and the teacher is remarkable: the former acquire a theoretical point of view about their practice and the latter, in his turn, seems to acquire a practical point of view about his theory, however not renouncing to it.
\end{abstract}


Keywords: vocational education, verbal interaction, teacher student-dialog. 